\section{NHS dental charges increases covering cuts and undermining prevention}

The government's decision to increase the cost of NHS dentistry has been met with heavy criticism by sectors of the profession.

The British Dental Association has slammed the latest above inflation increase in dental charges, announced last month. The Oral Health Foundation also called out the increase, labelling the price hike as a 'disgrace' and an appalling decision that will significantly impact the public's health.

The 5\% increase in charges will see the cost of a routine check-up increase by $£ 1.10$ to $£ 22.70$, and the cost for a set of dentures increase by $£ 12.80$ to $£ 269.30$.

Dentist leaders have castigated ministers over recent increases which have provided cover for sustained cuts in state contributions to NHS dentistry. Net government expenditure on services in England has fallen by nearly $£ 550$ million in real terms since 2010, while charges levels have increased by over $30 \%$ to plug the gap.

Charges for complex NHS treatment over the past 5 years have increased 4 times faster in England than in Wales. Fees for treatments in Bands 2 and 3 have gone up by $23 \%$ since 2014/15 in England and are expected to rise by only $7 \%$ in the same period in Wales.

Nearly 1 in 5 patients have delayed treatment for reasons of cost according to official statistics. Academic studies show 380,000 patients with toothache are choosing to head to their GPs, who are not subject to charges but are unequipped to provide dental treatment. The $\mathrm{BDA}$ estimates these appointments cost the NHS over $£ 20$ million a year. Some 135,000 patients per year are attending $A \& E$ units with dental problems.

The BDA's Chair of General Dental
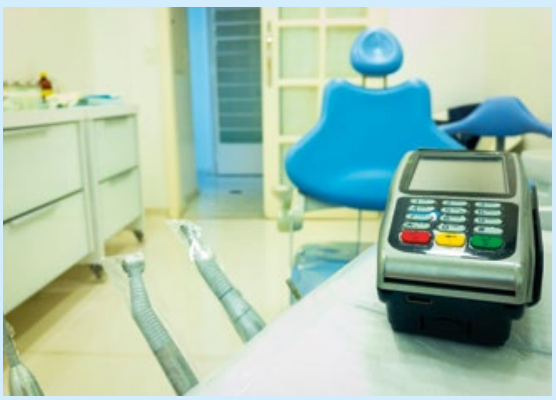

Practice Henrik Overgaard-Nielsen said: 'Despite pledges of record NHS investment, our patients are being singled out to pay more, just so ministers can pay less.

'These inflation-busting hikes don't put a penny of new investment into this service, and will do nothing for patients unable to find an appointment, or the practices struggling to recruit staff.

\section{'It is clear however, that the government continues to see it as a cash cow to prop up other areas of the health service.'}

'Dentists share the government's commitment to prevention, but we cannot make progress when low income, high needs patients keep being offered reasons not to attend.'

Dr Nigel Carter OBE, Chief Executive of the Oral Health Foundation, added: 'We have seen these price rises develop over many years and we fear it will soon push many of the population to breaking point.

'A significant U-turn needs to happen to make NHS dentistry more affordable. It is clear however, that the government continues to see it as a cash cow to prop up other areas of the health service.

'What makes this situation even more appalling is that while NHS charges for the public are increasing, investment is decreasing. NHS dentistry is dangerously underfunded and neglected by health ministers. It's overstretched and underequipped to effectively care for the nation's needs.

'In addition to lower NHS dental costs, these countries have also invested in preventive programmes which have been highly effective in reducing dental disease in children. The success of Childsmile in Scotland and Designed to Smile in Wales must be replicated in England. For this to happen, government must put an end to the heavy and sustained cuts to funding and show their commitment to the nation's oral health and wellbeing.'

\section{Costs up, profits down}

Latest figures suggest incomes are up but profits are down for practices across the UK.

That's according to the latest NASDAL

(National Association of Specialist Dental Accountants and Lawyers) Benchmarking Report for 2017/18, which shows a decrease of $3 \%$ in net profits for a typical dental practice. Whilst income for NHS and private practices has increased (although there was a slight reduction for mixed practices), there has been an increase in most expenses - notably associates' costs and wages.

NHS practices have fared the worst having seen average total fee income per dentist drop from $£ 181,804$ in 2017 to $£ 169,615$.

Ian Simpson, Chartered Accountant and a partner in Humphrey and Co, which carries out the statistical exercise commented: 'Although profits are down across all types of practices, it is clear that there is a big divide between private practices and those that are NHS and mixed. Private practices saw a reduction in profit of just $0.5 \%$ whereas both NHS and mixed practices saw reductions of around $10 \%$. Interestingly, mixed practices typically have the highest level of fee income, but they also have the highest cost ratios.'

\section{Associates - BREXIT effect?}

The report has also seen the first real rise in associate profitability for many years. Associates have been used to their earnings flatlining for more than a decade but 2017/18 has seen that turn around. In some areas of the country this will have been caused by associates being in more short supply and thus their bargaining power increasing.

Income has increased by more than $6 \%$ for associates but this has only translated into a small net profit rise of just under $£ 2,000$ per annum as outgoing expenses have increased for associates in the same way that they did for practices.

Nick Ledingham, of Morris \& Co, Specialist Dental Accountants and Chairman of NASDAL observed: 'It seems that the costs of running a dental practice are on the rise and that revenues have not yet increased to keep pace. It is important that dental practices take specialist advice so that they can understand and react to changes in their business situation.' 